\title{
A POLÍTICA ENERGÉTICA ALEMÃ - EXEMPLO EUROPEU DE SUSTENTABILIDADE?
}

\author{
Ana Isabel Gouveia BOURA \\ CITCEM / Faculdade de Letras da Universidade do Porto \\ aboura@letras.up.pt
}

\begin{abstract}
Resumo
A transição energética para as energias renováveis tem constituído objetivo privilegiado na política governamental da Alemanha reunificada. $\mathrm{Na}$ ação concertada de diversos ministérios, sucedem-se as medidas que visam uma progressiva substituição dos combustíveis fósseis e nucleares por energias renováveis. Ao investimento estatal nas estruturas de produção, distribuição e armazenamento energéticos, junta-se $o$ apoio governamental aos consumidores de energia, que, assim, beneficiam quer de amplas ações informação, quer de distintos programas de incentivo. Tal esforço governamental alemão em prol das energias regenerativas não se reduz ao plano interno: tanto enquanto membro de instituições internacionais, como através de iniciativas de cooperação científica e económica, a República Federal da Alemanha partilha com países de todos os continentes a experiência bem sucedida da sua nova política energética.
\end{abstract}

Palavras-chave: Alemanha, energias renováveis, sustentabilidade

\begin{abstract}
:
The energy transition to renewable energies has been a prime objective in the government policy of reunified Germany. In the concerted action of various ministries, important measures have been taken to gradually replace fossil and nuclear fuels with renewable energy. To state investment in energy production, distribution and storage the German government adds support to energy consumers, who thus benefit from extensive information and incentive programs. Such governmental effort to use regenerative energies is not limited to the internal plane: in meetings of international institutions, as well as through cooperation projects, the Federal Republic of Germany shares with countries on all continents the successful experience of its new energy policy.
\end{abstract}

Keywords: Germany, renewable energies, sustainability

\section{Reforma do setor energético}

Intimamente associada ao tema das alterações climáticas - cada vez mais premente na atualidade política, económica e mediática internacional -, a expressão energias renováveis assoma, com crescente frequência, nas resoluções emanadas de cimeiras intergovernamentais, nas iniciativas projetadas por agentes macroeconómicos e nos textos informativos divulgados pela televisão, pela rádio, pela imprensa e pela internet. 
Tanto mais, por conseguinte, se impõe a múltipla interrogação: a que nos referimos, quando falamos em energias renováveis? Que pretendemos significar com o termo renovável? Saberão os cidadãos europeus, como os norte-, centro- e sul-americanos, ou os asiáticos e os africanos adereçados nas agendas político-económicas, nos projetos científicos e tecnológicos e nos programas da comunicação social - enunciar exemplos de energias renováveis, apontar vantagens de tais fontes energéticas, indicar as nações que, em maior grau, ameaçam o equilíbrio climácticoambiental, nomear os países que, com maior eficácia, procedem à implementação sistemática de energias renováveis? Ou, em pergunta menos abrangente, mas não menos direta: estarão os habitantes da velha Europa conscientes de que as energias renováveis constituem, indubitavelmente, uma das grandes problemáticas do espaço europeu?

A resposta a tal conjunto de questões variará consoante o enquadramento geográfico, a moldura politico-ideológica, o estatuto socioeconómico e a formação cultural dos potenciais inquiridos. E se, no concerto europeu, a República Federal da Alemanha avulta como signo de estabilidade política, desenvolvimento económico, avanço científico e progresso tecnológico, não surpreenderá, decerto, que os cidadãos germânicos acusem, em matéria de energias renováveis, não só mais elevado nível de informação, mas também superior benefício, pela implementação precursora e sistemática de energias alternativas.

Justifica-se, assim, de imediato, a interrogação de espectro simultaneamente diacrónico e sincrónico: como se preparou a Alemanha reunificada para a renovação do seu sistema energético? Que importância assumem na Alemanha de hoje as energias renováveis? Que implicações futuras traz, no plano nacional, no âmbito da EU e no palco transeuropeu, o recurso da República Federal da Alemanha a estas fontes de energia?

As agendas políticas e económicas internacionais em torno das problemáticas do clima e do ambiente deixam bem evidente que o século XXI constitui o século da descarbonização. Multiplicamse, em sucessivos encontros de agentes políticos, económicos, sociais e culturais, os apelos incisivos ao recurso global de energias regenerativas, apontadas como pressuposto essencial e garante primordial de sustentabilidade ambiental e económica.

Tal insistência multilateral em energias alternativas não surpreende, porquanto à crescente degradação do ecossistema se junta a progressiva escassez universal das fontes energéticas convencionais, em iniludível contraste com a sustentabilidade dos recursos energéticos naturais. De facto, as energias renováveis apresentam-se abrangente e permanentemente disponíveis, pois que a maioria dos países aufere de sol, água, vento, biomassa e geotermia em quantidades muito superiores à crescente procura mundial de energia.

A reforma do setor energético constitui a resposta nacional da República Federal da Alemanha ao problema global das alterações climáticas e do desgaste ambiental. Sob a designação lapidar Energiewende, em tradução literal: viragem energética, se congregam os objetivos governamentais que fundamentam e balizam a política energética da Alemanha definida para a primeira metade do século XXI.

São, neste sentido, propósitos orientadores das agendas políticas alemães a redução das emissões de gases $\mathrm{CO} 2$, pelo recurso decrescente a fontes energéticas convencionais, 
designadamente, aos combustíveis fósseis e à energia nuclear, e pela consequente utilização crescente de energias regenerativas; a construção e / ou modernização de novas redes de transporte e de distribuição de energia; a integração das energias renováveis no mercado nacional, a custo sustentável, a disponibilização de energias renováveis a todos os consumidores nacionais e a garantia de abastecimento energético sem rutura, qual seja a momentânea situação atmosférica; a ação concertada de entidades governamentais e municipais, agentes económicos, organizações científicas e tecnológicas e da sociedade civil; a cooperação, no setor das energias regenerativas, com estados dos continentes europeu, africano, asiático e americano, através de parcerias nacionais e regionais.

A Lei para a Implementação das Energias Renováveis (Gesetz für den Ausbau erneuerbarer Energien), abreviadamente, Lei das Energias Renováveis (Erneuerbare-Energie-Gesetz, EEG), em vigor desde 2000 e sucessivamente revista (EEG 2004, EEG 2009, EEG 2012, PV-Novelle, EEG 2014, EEG 2017), constitui a grande linha de orientação no processo de implementação de energias renováveis na República Federal da Alemanha. São objetivos fundamentais consignados no texto legal o recurso progressivo a fontes de energia regenerativa, a modernização infraestrutural, a inovação tecnológica, a integração competitiva das energias renováveis no mercado nacional e a competitividade internacional do setor energético alemão. A EEG 2017 prevê a desativação de todas as centrais nucleares em solo alemão até 2022, atribuindo aos exploradores das instalações produtoras os encargos da desativação e do embalamento dos resíduos tóxicos e conferindo ao Estado a responsabilidade pelo armazenamento temporário e definitivo dos mesmos.

$\mathrm{Na}$ senda da Lei das Energias Renováveis (Erneuerbare-Energie-Gesetz, EEG) se situam a Agenda de 10 Pontos da Viragem Energética (10-Punkte-Agenda der Energiewende), datada de junho de 2014 e revista e aumentada em janeiro de 2016, que lista e calendariza os objetivos centrais da transição energética, e a Lei do Mercado Energético (Strommarktgesetz), promulgada em julho 2016, que enuncia os procedimentos conducentes à flexibilidade da produção, da distribuição e do consumo energéticos.

\section{Implementação das energias renováveis}

Consideravelmente ambiciosos, tais múltiplos objetivos impõem um vasto conjunto de medidas, distribuídas por numerosos órgãos institucionais e desdobradas em distintos, mas concertados programas de ação.

Refira-se, antes de mais, a construção e a renovação de instalações geradoras de energia renovável, nomeadamente, coletores solares, parques eólicos terrestres e marítimos, centrais hídricas e instalações geotérmicas. Prepondera o recurso à energia eólica, à energia solar e à biomassa, sendo, no aproveitamento solar, especialmente relevantes as instalações fotovoltaicas, em detrimento de grandes centrais solares, pela baixa quantidade de radiação anualmente recebida em território alemão. Não obstante, também a utilização de energia hídrica, no setor elétrico, e de energia geotérmica, no setor do aquecimento e da refrigeração, a par do uso de biocombustíveis, no setor 
dos transportes, assume considerável importância no programa alemão de sustentabilidade energética.

Aponte-se, por outro lado, a criação das designadas autoestradas energéticas - milhares de quilómetros de redes de transmissão elétrica, que, privilegiando cabos subterrâneos e submarinos, em detrimento dos tradicionais cabos aéreos, e substituindo a corrente trifásica por corrente contínua, sulcarão transversalmente o país, possibilitando, por exemplo, quer a ligação dos parques eólicos, maioritariamente localizados no norte e leste da Alemanha, com os maiores centros de consumo energético do território germânico, situados a sul e oeste, quer a transmissão para norte de energia produzida em instalações fotovoltaicas sediadas a sul. Deste modo se pretende e se providencia que as energias regenerativas cheguem, a todo o momento, a cada tomada dos consumidores alemães.

O traçado e a execução de tais redes transmissoras ficam a cargo de consórcios europeus do setor, sob a supervisão da Agência Federal de Redes de Eletricidade, Gás, Telecomunicações, Correio e Ferrovia (Bundesnetzagentur, BNetzA) e com subsidiação da União Europeia, não sem ampla consulta prévia de especialistas externos e da sociedade civil, que, aliás, não se escusou a apontar, nos planos, reparos relativos ao eventual impacto ambiental e geológico, obrigando à correção dos traçados inicialmente previstos e, deste modo, determinando o significativo adiamento dos prazos de construção.

Constituem aqui projetos de maior envergadura o SuedLink, destinado a transportar energia eólica desde o estado alemão de Schleswig-Holstein, a norte, até aos estados de BadenWürtemberg, a sudoeste, e da Baviera, a sul, numa extensão de cerca de $700 \mathrm{kms}$; o SuedOstLink, que garantirá a transmissão energética entre os estados de Saxónia-Anhalt, a nordeste, e da Baviera, numa extensão de cerca de 580 kms; e o NordLink, que irá ligar a Alemanha setentrional à Noruega, pelo transporte recíproco de energia eólica alemã e energia hídrica norueguesa, numa extensão de cerca de $623 \mathrm{kms}$.

Ressalte-se, paralelamente, a monitorização digital do setor das energias renováveis, estipulada na Lei para a Digitalização da Transição Energética (Gesetz zur Digitalisierung der Energiewende), de 29 de agosto de 2016, que gere a adaptação do sistema de provimento de energia à transição para as energias renováveis. Com vista à coordenação eficaz de produção, distribuição e consumo energéticos, e, deste modo, ao armazenamento de reservas para quadros climáticos imprevisíveis, porque diretamente dependentes das eventuais condições atmosféricas, como seja o abastecimento de energia em dias sem sol, ou sem vento, o Estado alemão promove a vinculação digital de produtores, distribuidores e consumidores de energias regenerativas, apoiando a implementação da tecnologia digital Smart Grid. Pela comunicação em rede, através de sistemas digitais, das centrais de produção, das redes de distribuição e dos aparelhos de consumo, de forma a calibrar continuamente a oferta e a procura, garante-se a informação atualizada, quase em tempo real, sobre que aparelho, em que momento, utiliza quanta energia, ou seja, possibilita-se a indicação de qual a quantidade de energia disponível em cada situação espacial e em cada lapso temporal.

Para o efeito de monitorização, foi desenvolvido o designado Smart-Metering-System, um sistema inteligente de medição digital do consumo energético, que, em substituição dos contadores tradicionais, procede à medição contínua do consumo energético, proporcionando uma base geral de 
dados e concorrendo, deste modo, para a utilização otimizada de energia. Os primeiros aparelhos de Smart-Metering-System foram colocados, em 2017, nas instalações de grandes produtores e consumidores, prevendo-se que, a partir de 2020, sejam disponibilizados nos espaços domésticos de maior consumo energético.

Constitui firme propósito governamental a promoção de uma observação contínua e pormenorizada da transição energética alemã. A reunião de dados relativos à utilização nacional das energias regenerativas numa base ampla e sincronizada e a configuração de estatísticas a partir das informações recolhidas estão a cargo do Grupo de Trabalho Estatísticas de Energias Renováveis (Arbeitsgruppe-Erneuerbare-Energien-Statistik, AGEEStat), um grémio independente de especialistas, criado em 2004, que reúne membros de diversos órgãos governamentais, nomeadamente do Ministério Federal para a Economia e a Energia (Bundesministerium für Wirtschaft und Energie, BMWi), do Ministério Federal para o Ambiente, a Proteção da Natureza e a Segurança Nuclear (Bundesministerium für Umwelt, Naturschutz und nukleare Sicherheit, BMU), do Ministério Federal para a Nutrição e a Agricultura (Bundesministerium für Ernährung und Landwirtschaft, BMEL) e do Gabinete Federal do Ambiente (Umweltbundesamt, UBA), mas também do Gabinete Federal de Estatística (Statistisches Bundesamt, StBA), da Agência Federal de Redes de Eletricidade, Gás, Telecomunicações, Correio e Ferrovia (Bundesnetzagentur, BNetzA), da Agência Especializada de Recursos Regenerativos (Fachagentur Nachwachsende Rohstoffe, FNR), da Sociedade de Trabalho Relatórios de Energia (Arbeitsgemeinschaft Energiebilanzen, AEEB) e do Centro para a Investigação sobre Energia Solar e Recursos Hídricos de Baden-Würtemberg (Zentrum für Sonnenenergie und Wasserstoff-Forschung Baden-Würtemberg, ZSW).

No sentido de possibilitar a produtores, comercializadores e consumidores de energia uma informação pertinente quer sobre o curso do mercado energético alemão, quer sobre e evolução do setor das energias renováveis na República Federal da Alemanha, foi criada a SMARD, uma plataforma informativa, desde julho de 2017 online, que procede à ampla divulgação de dados abrangentes e atuais relativos à produção, à comercialização e ao consumo energéticos em território nacional. Para facilitar o acesso dos utentes aos indicadores apresentados, devidamente avalizados pela Agência Federal de Redes de Eletricidade, Gás, Telecomunicações, Correio e Ferrovia (Bundesnetzagentur, BNetzA), a plataforma não apenas recorre a gráficos de fácil leitura, como também disponibiliza artigos de fundo suscetíveis de esclarecerem aspetos conceituais e metodológicos pertinentes. Os utilizadores da plataforma SMARD encontram, assim, respostas acessíveis e permanentemente atualizadas sobre a tipologia, a capacidade e localização (regional e nacional) de fontes de energia, sobre os níveis e os custos de consumo energético, sobre as rotas e os volumes de importação e exportação alemãs no setor da energia.

Aos consumidores privados de energia elétrica cabe, desde 2003, uma parcela contributiva no investimento estatal em energias renováveis. De facto, a fatura mensal de energia paga pelos consumidores finais não estatais inclui a designada EEG-Umlage, uma quota extraordinária destinada a aliviar o esforço estatal de transição energética. Anualmente determinado pelas empresas de distribuição de eletricidade, de acordo com o previsto na Lei das Energias Renováveis (ErneuerbareEnergie-Gesetz, EEG), o suplemento resulta da diferença entre as receitas e despesas do 
abastecimento elétrico, tendo sofrido sucessivos aumentos desde a sua introdução, mas apresentando, nos últimos anos, uma leve, porém continuada redução. Note-se, a título ilustrativo, que o montante da parcela extra orçava, em 2017, 6,880 ct / Kwh, sendo, em 2018, 6,792 ct / Kwh e, em 2019, 6,405 ct / Kwh.

Não faltam, todavia, medidas de apoio estatal no âmbito energético, realizadas através de programas diversificados, que incentivam quer a investigação científica em tecnologias de ponta, quer o investimento em instalações de geradoras de energia, quer a informação sobre eficiência energética.

Constitui, desde logo, aqui exemplo a Regulamentação Especial de Compensação (Besondere Ausgleichungsregelung), que, consignada na Lei das Energias Renováveis (Erneuerbare-EnergieGesetz, EEG 2017) e anualmente adaptada, possibilita a empresas com elevados custos de energia elétrica e a empresas de transporte sobre carris auferirem uma redução da quota extraordinária para o financiamento da transição energética. Mas também indivíduos ou grupos não empresariais, como sejam organizações de utilidade pública, cooperativas de habitação, proprietários de imóveis, profissões liberais ou consumidores domésticos beneficiam de apoio financeiro no seu recurso sistemático a energias renováveis.

São, por outro lado, ilustrativos os numerosos programas de divulgação e aconselhamento, destinados ao esclarecimento geral dos cidadãos. Tal informação é disponibilizada tanto em gabinetes urbanos de atendimento personalizado, como através de publicações de pequena dimensão e em linguagem despretensiosa - brochuras, flyers - emanadas de fontes governamentais, ou provenientes de organizações estatais afins, e colocadas gratuitamente à disposição dos cidadãos em sites oficiais da responsabilidade de diversos Ministérios Federais. Destacam-se, no manancial de materiais informativos, por um lado, os portais Energias Renováveis (Erneuerbare Energien) e $A$ Alemanha age com eficiência (Deutschland macht's effizient), e, por outro lado, as publicações em formato digital Quem é quem da viragem energética na Alemanha. Interlocutores na política, economia e sociedade (Who is who der Energiewende in Deutschland. Ansprechpartner in Politik, Wirtschaft und Gesellschaft), ou Livro Verde Eficiência Energética (Grünbuch Energieeffizienz).

A eficiência energética constitui, de facto, diligência central no processo político alemão de transição energética. Com o propósito de promover a redução do consumo energético nos diversos setores estatais e privados, o governo alemão federal apresentou, em 2007, O Plano Nacional de Ação Eficiência Energética (Nationaler Aktionsplan Energieeffizienz, NAPE), que, sucessivamente revisto, aponta, um conjunto de medidas promotoras de poupança energética, nomeadamente pela utilização consciente de energia e pelo investimento em requisitos energeticamente eficientes.

Ao investimento financeiro estatal na eficiência do sistema energético, que se prevê orçar, até 2020, cerca de dezassete mil milhões de euros, junta-se o repto governamental aos usuários privados em prol do uso eficiente de energia. As empresas são, assim, por exemplo, incentivadas à significativa redução de custos pela aquisição de equipamentos eficientes e pela adoção de processos otimizados. Dados fornecidos pela Agência Alemã de Energia (Deutsche Energie-Agentur, dena) evidenciam, nos últimos anos, sintomática diminuição das despesas energéticas no setor 
industrial - uma vantagem não só em termos de mercado interno ou externo alemão, como ainda uma significativa contribuição para a sustentabilidade ambiental global.

Também os consumidores em espaços domésticos, comerciais e de serviços são, por exemplo, aconselhados, através de múltiplos canais estatais, a procederem à substituição dos seus aparelhos elétricos com utilização superior a dez anos por aparelhos de consumo otimizado, ou a fazerem a comparação de tarifas dos fornecedores de energia. Significativamente, em 2015, cerca de quatro milhões de consumidores optaram por alterar o seu contrato de fornecimento energético, ou por mudar de empresa fornecedora.

Com idêntico intuito de aumentar a eficiência energética, foi, em novembro de 2015, apresentada a Estratégia de Eficiência Energética dos Imóveis (Energieeffizienzstrategie Gebäude, ESG), um plano estratégico para a viragem energética no setor imobiliário, focado no objetivo governamental de que o parque imobiliário alemão atinja, em 2050, pelo consumo eficiente de energia e pela implementação de energias renováveis, o estatuto de neutralidade climática.

Neste sentido, os proprietários de imóveis e os arrendatários são elucidados sobre a necessidade de garantirem a impermeabilização dos telhados e das fachadas e a calafetação das janelas e de optarem por um sistema otimizado de eletricidade e de aquecimento / refrigeração. Através do Financiamento do [Banco] KfW para a Reabilitação de Edifícios (KfW-Förderung für Gebäudesanierung), os governos da Alemanha reunificada têm financiado a modernização energética dos edifícios existentes, mas também a construção de novos imóveis, ultrapassando já os 4,6 milhões o número de edifícios contemplados, num volume global de investimento superior a 270 mil milhões de euros.

Cerca de 35\% do consumo final de energia na República Federal da Alemanha cabe, de facto, a edifícios. No respeitante aos edifícios novos, o Estado alemão não apenas apela à boa impermeabilização e calafetação das zonas interfaciais, como ainda requer um abastecimento elétrico e térmico com recurso às energias regenerativas, defendendo nomeadamente a utilização de energia geotérmica para aquecimento das habitações, seja através da instalação de bombas para captação de calor subterrâneo em zonas próximas da superfície terrestre, seja por geotermia remota, com captação de calor em regiões geológicas mais profundas. Porque mais dispendiosas, as instalações geotérmicas de captação profunda beneficiam de apoio financeiro estatal consignado, desde logo, na Lei de Energias Renováveis (Erneuerbare-Energie-Gesetz, EEG) e agilizado pelo Programa de Incentivo do Mercado (Marktanreizprogramm, MAP).

Embora fração menos significativa, no consumo energético, do que as parcelas da energia elétrica (pública e privada) e da energia térmica (especialmente convocada para o aquecimento e a refrigeração de espaços domésticos), a fatia energética dos transportes atinge valores internacionais não despiciendos, colocando o setor no conjunto das maiores ameaças ambientais. Daí a atenção prestada pelo Estado alemão aos modos de abastecimento nacional de automóveis, comboios, barcos e aviões, fomentando a utilização estatal e privada de biocombustíveis, como sejam o álcool etílico, o biodiesel e o biogás, e favorecendo o crescente recurso à eletromobilidade. Significativamente, o portal alemão Statista indica que o número de viaturas elétricas, registadas, em 
2018, na Alemanha ascendeu a 53861 unidades, um valor superior, em quase 58\%, ao índice homólogo do ano antecedente.

Para melhor assegurar o apoio financeiro a todos os consumidores de energia, o Estado alemão não descura a contenção das despesas orçamentais impostas pela transição energética, procurando estrategicamente atenuar tal esforço. Assim se entende a implementação de concursos públicos regulares, em regra trimestrais, para a construção e manutenção de centrais de produção de energias renováveis, através dos quais se logra a redução progressiva da participação estatal: a subsidiação governamental é calculada a partir do resultado de cada concurso público. Escolhidos são os candidatos que apresentarem orçamentos mais baixos, sem prejuízo da qualidade e da eficiência energéticas. Em resultado, por exemplo, a média de financiamento estatal para instalações fotovoltaicas desceu, nos últimos anos, quase $30 \%$.

\section{Impulsos da viragem energética}

Sobremaneira custosa, quer pelas drásticas remodelações estruturais, quer pelos avultados custos orçamentais, a viragem energética da República Federal da Alemanha afigura-se, antes de mais, relevante motor de inovação, pois que estimula e sustenta a pesquisa, o desenvolvimento e a aplicação de novas tecnologias. Numerosos centros de investigação científica delineiam, em coordenação com firmas altamente especializadas, novos modelos operativos e instrumentais. Não surpreende, por conseguinte, o número anual crescente de novas patentes no âmbito da alta tecnologia germânica para o setor energético.

Ciente de que a produção, o transporte, a distribuição, o armazenamento e o consumo de energia, no quadro da transição para um sistema energético ecológica, económica e socialmente sustentável, requerem novas soluções tecnológicas, o governo alemão apoia a pesquisa, o desenvolvimento e a experimentação de tecnologias inovadoras, por exemplo, através do Programa de Investigação sobre Energia (Energieforschungsprogramm). Iniciada em 1977, na senda da primeira crise petrolífera, a edição estreante do programa almejava contributos de investigação para a diminuição das importações alemãs no setor da energia, a redução do consumo energético nacional e a diversificação de fontes de energia, com especial valorização das energias não nucleares.

A sétima edição do programa, promulgada, após ampla consulta de parceiros políticos, económicos e científicos, em setembro de 2018, contempla o período de 2018 a 2022 e pretende apoiar projetos desenvolvidos não apenas em universidades, ou em centros científicos, mas também em empresas, já consolidadas ou start-ups, do setor. Disponibilizado por três Ministérios - o Ministério Federal para a Economia e a Energia (Bundesministerium für Wirtschaft und Energie, BMWi), o Ministério para a Cultura e a Investigação (Bundesministerium für Bildung und Forschung, BMBF) e o Ministério para a Nutrição e a Agricultura (Bundesministerium für Ernährung und Landwirtschaft, BMEL), o montante de financiamento previsto ronda os 6,4 mil milhões de euros - superior, em cerca de $60 \%$, ao valor orçamentado para a sexta edição do programa, que abrangeu o período de 2013 a 2017, e constituindo quase 50\% da quantia disponibilizada entre1977 e 2017. 
Concomitantemente, a implementação de energias renováveis revela-se importante motor de desenvolvimento económico. Com efeito, a mudança energética alemã movimenta, por um lado, investimentos nacionais, em distintas áreas, no valor de milhares de milhões de euros e promove, por outro lado, a abertura de novas áreas de mercado interno, sobretudo nos setores do comércio e da indústria. A constante necessidade de materiais de construção e de apetrechamento, de aparelhos originais e peças de substituição, de obras de montagem e serviços de manutenção traduz-se, ademais, no mercado de trabalho, justificando o sucessivo aumento de postos laborais. Informação colhida no portal governamental Energiewende direkt revela que, em 2016, o setor das energias renováveis empregava, direta e indiretamente, 338600 trabalhadores.

Repercussão positiva assume o recurso às energias regenerativas igualmente na balança comercial da República Federal da Alemanha, seja pela progressiva redução da importação de matérias primas fósseis e nucleares, seja pela oportunidade de exportação de requisitos tecnológicos e de know how. Sabidamente, as empresas alemãs de produtos e serviços no setor energético distinguem-se internacionalmente pela inovação, eficiência e sustentabilidade de equipamentos e processos. O selo made in Germany, que guindou, no final do século XIX, a Alemanha Guilhermina a primeiro lugar da indústria mundial, surge, no atual mercado das energias renováveis, como garantia máxima de pioneirismo, excelência e sustentabilidade.

A implementação das energias regenerativas exige uma atuação concertada à escala nacional e internacional. E a República Federal da Alemanha beneficia, também no domínio das energias renováveis, da sua situação geográfica no centro da Europa. De facto, fazendo fronteira com a França, a Holanda, a Bélgica, o Luxemburgo, a Suíça, a Áustria, a Republica Checa, a Polónia e a Dinamarca, o estado alemão encontra-se no cerne de uma rede energética europeia, que ativamente persegue a remodelação do sistema energético.

De facto, o êxito do processo global de transição energética pressupõe a participação ativa de todos os atores políticos, os parceiros económicos e os grupos sociais, num diálogo concertado, gerido por plataformas nacionais, mas também internacionais. Precisamente, no domínio das energias renováveis, a Alemanha mantém estreita e frutuosa colaboração, não apenas com os seus nove estados vizinhos, mas também com a Suécia e a Noruega, o que permite, por exemplo, conjugar produtivamente a energia hídrica dos países escandinavos e alpinos com a energia eólica e a energia fotovoltaica alemãs.

Significativamente, em 2016, o governo alemão procedeu, no quadro de uma cooperação piloto, à abertura bilateral de concursos para instalações de energia solar com sede simultaneamente na Dinamarca e em território alemão. Conduzidos pela Agência Federal de Redes de Eletricidade, Gás, Telecomunicações, Correio e Ferrovia (Bundesnetzagentur, BNetzA) e pela sua congénere dinamarquesa, tais concursos constituíram os primeiros concursos transfronteiriços no setor das energias renováveis no espaço europeu, preparando já o governo alemão semelhantes iniciativas transnacionais também no setor da energia eólica.

A República Federal da Alemanha participa ativamente no programa de convergência energética dos vinte e oito estados-membro da União Europeia. Ilustra tal empenhamento germânico no projeto europeu para a sustentabilidade ambiental e para a estabilização climática, antes de mais, 
o cumprimento estrito dos objetivos gerais conjuntamente enunciados, mas, não menos, a implementação de medidas específicas suscetíveis de reforçarem e acelerarem os propósitos comunitários. Saliente-se, exemplificativamente, a abertura estatal de concursos transfronteiriços com sede fora do território alemão: $5 \%$ dos concursos públicos alemães destinados à instalação anual de centrais de energia renovável visam apoiar a construção de centrais de produção energética com sede em outros estados-membro da UE.

Não se reduzem, obviamente, ao âmbito europeu as iniciativas alemãs de cooperação no setor energético. Enquanto membro de numerosas organizações internacionais, várias delas especificamente orientadas para o setor energético, como sejam a International Energy Agency (IEA) e a International Renewable Energy Agency (IRENA), a República Federal da Alemanha trabalha em estreita colaboração com países dos vários continentes, que, através de parcerias nacionais e / ou regionais, beneficiam da experiência alemã de transição energética. E, se os estados alvo de cooperação, ganham com o apoio financeiro, tecnológico e humano do Estado germânico, as empresas germânicas logram, em contrapartida, a entrada, com apoio governamental, em mercados internacionais recetivos a tecnologias inovadoras, eficientes e sustentáveis.

Merece aqui particular referência o programa Iniciativa à Exportação (Exportinitiative), sob a égide do Ministério Federal para a Economia e a Energia (Bundesministerium für Wirtschaft und Energie, BMWi), que incentiva empresas alemãs de novas tecnologias no setor energético a procurarem mercados de exportação à escala internacional. Auferem, neste caso, apoio preferencial as empresas de pequena e média dimensão, com sede na Alemanha, que ofereçam soluções energéticas inovadoras e sustentáveis, sobretudo na área das energias regenerativas e no domínio da eficiência energética, mas também no respeitante a redes digitais e tecnologias de armazenamento de energia. Através do programa, que aposta na divulgação e no aconselhamento, mas também na pós-formação, as empresas veem facilitados a procura de parceiros, o estabelecimento de contactos e a consolidação de relações de âmbito externo.

Em 2017, a Alemanha aproveitou também a presidência do G20, que precisamente agrupa países industrializados, países emergentes e países em desenvolvimento, para dinamizar uma reflexão sistemática sobre a transição das energias convencionais para as energias ecológicas, aproximando, deste modo, o grupo de estados-membro dos objetivos enunciados na Declaração do Rio de Janeiro (1992), na Declaração do Milénio (Nova lorque, 2000), no Tratado de Paris (2015) e na Agenda 2030 (Nova lorque, 2015).

Neste mesmo sentido, o governo alemão, através do Ministério Federal para a Economia e a Energia (Bundesministerium für Wirtschaft und Energie, BMWi) e do Ministério das Relações Exteriores (tradução aproximada da denominação oficial Auswärtiges Amt) e em conjugação com a Associação Alemã Federal das Energias Renováveis (Bundesverband Erneuerbare Energie, BEE), a Associação Alemã Federal do Setor Solar (Bundesverband Solarwirtschaft, BSW-Solar), a Agência Alemã de Energia (Deutsche Energie-Agentur, dena) e a firma de consultoria empresarial eclareon, promove, desde 2015, o congresso anual Berlin Energy Transition Dialogue, que convoca dezenas de entidades estatais e não estatais para uma abordagem fundamentada e dinamizadora dos múltiplos aspetos que informam a viragem energética à escala global. Ao longo de dois dias, membros de 
governos, administradores de empresas, presidentes e diretores de agências e institutos dos vários continentes discutem experiências, projetos e modos viáveis de transformação sustentável do sistema energético.

Por demais ilustrativo se afigura o Berlin Energy Transition Dialogue 2018, desde logo, pelo número e pela relevância dos participantes, cerca de dois mil, sendo aqui pertinente destacar, no programa, o conjunto de oradores: aos ministros alemães responsáveis pela pasta da economia e da energia juntaram-se homólogos da Etiópia, Finlândia, Geórgia, Grécia, Jordânia, Lituânia, Macedónia, Noruega, Polónia, Roménia, Tailândia, Tunísia, Turquia e Mianmar, do Bangladesh, Gana, México e Uganda e dos Emirados Árabes Unidos. Aos ministros germânicos a cargo do ambiente e das relações externas agregaram-se os respetivos pares da Costa Rica, do Sri Lanka e dos Camarões. Secretários de Estado vieram da Espanha, França e Suécia, de Marrocos e do Kuwait; outros representantes governamentais chegaram da China, Índia, República da Coreia e do Egito. ${ }^{1}$ Integraram igualmente o grupo de oradores altos dirigentes de grupos industriais, associações comerciais, instituições financeiras, organizações não governamentais e centros de investigação, com sede em países dos diversos continentes e distinguidos por excelente qualificação nas áreas da produção e do abastecimento energéticos, da consultoria tecnológica, financeira e jurídica, da pesquisa científica, do investimento e da cooperação. ${ }^{2}$

Saliente-se que o Berlin Energy Transition Dialogue se inscreve na Berlin Energy Week, no decurso da qual se realizam eventos que precedem, acompanham e se seguem a cada congresso anual, designadamente, visitas guiadas, workshops e encontros interempresariais. Em número avultado - dez, na edição de 2018 -, as visitas guiadas permitem aos participantes não apenas o contacto direto com dirigentes empresariais, agentes de investimento e investigadores científicos, mas também uma perceção in loco dos cenários mais avançados e dos projetos mais auspiciosos que configuram a viragem energética alemã.

\section{Exemplo europeu de sustentabilidade}

São, nas circunstâncias acima expostas, por de mais relevantes e promissores, os resultados do esforço governamental alemão de reconversão energética. De facto, em janeiro de 2017, a maioria dos objetivos enunciados na Lei para a Implementação das Energias Renováveis (Gesetz für den Ausbau erneuerbarer Energien) encontrava-se realizada, sendo marcante a progressiva redução do consumo energético nacional, apesar do concomitante crescimento do PIB alemão, e o aumento da participação das energias renováveis na produção e no consumo final de energia.

Assim, segundo dados fornecidos pela Repartição Federal do Ambiente (Umweltbumdesamt, UBA), a parcela de energias renováveis no consumo nacional bruto de energia elétrica foi, em 2016, de $31,6 \%$ e, em 2017 , de $36,0 \%$. No setor do aquecimento e refrigeração, a fatia de energias

\footnotetext{
${ }^{1}$ Contrariando a versão do programa datada de 06.04.2018, na qual constava o nome do Secretário de Estado da Energia de Portugal, Dr. Jorge Seguro Sanches, a integrar a mesa subordinada ao tema Carbon Pricing, a agenda programática com data de 16.04.2018 não referencia qualquer membro do governo português.

${ }^{2}$ O programa do Congresso, não referencia, nem na versão de 06.04.2018, nem na versão do dia 16.04.2018, qualquer entidade pública, ou estatal portuguesa.
} 
regenerativas constituiu, em 2016, 13,6\% e, em 2017, 13,9\%. Menos elevado, o valor das energias renováveis no setor dos transportes rondou, em 2016 e 2017, os 5,2\%. São metas governamentais que, no cômputo nacional de produção energética, a produção alemã de energias regenerativas, fique entre os $40 \%$ a $45 \%$ em 2020 , se situe entre os $55 \%$ a $60 \%$ em 2035 e se salde em $85 \%$ a $90 \%$ em 2050.

Em resultado do crescente recurso a energias renováveis, a emissão de gases com efeito de estufa na República Federal da Alemanha diminuiu consideravelmente. Com efeito, segundo informação divulgada pela Repartição Federal do Ambiente (Umweltbumdesamt, UBA), a utilização de energias regenerativas permitiu, em 2017, evitar a emissão de gases CO2, ou equivalentes, em cerca de 135 milhões de toneladas, no setor da eletricidade, 35 milhões de toneladas, no setor do aquecimento e refrigeração, e 7,4 milhões de toneladas no setor dos transportes. No Plano de Proteção Climática 2050 (Klimaschutzplan 2050), aprovado em novembro de 2016, o governo federal compromete-se a promover ativamente a redução de gases carbónicos nos setores da energia agrícola, industrial, imobiliária e dos transportes, prevendo-se que, relativamente a 1990, as emissões de CO2 diminuam 40\% até $2020,55 \%$ até 2035 , 70\% até 2040 e $80 \%$ a $85 \%$ até 2050 .

A viragem energética constitui hoje não apenas um dos principais projetos de investimento da República Federal da Alemanha, mas também um modelo de repercussão internacional, pelo resoluto decréscimo do recurso ao carvão, ao petróleo, ao gás e ao urânio, pela adoção de um sistema flexível de produção energética, pela eficaz coordenação digital de produção, distribuição e consumo, pela garantia de ininterrupto abastecimento nacional.

O número exponencial de encontros nacionais e internacionais em torno das questões ambientais e climáticas, o vasto conjunto de resoluções consignadas em tratados e em parcerias globais ou regionais, que apologizam a redução, quando não a eliminação, de emissões de gases carbónicos, pela progressiva e cabal substituição de combustíveis fósseis e nucleares por fontes de energia regenerativa, justificam que o século 21 seja já universalmente apelidado de século da descarbonização - epíteto eufórico, para os defensores da sustentabilidade ecológica, mas também disfórico, para os guardiães da multissecular herança industrial. E, contudo, pode, sem receio, afirmar-se que o presente século não ficará nos anais da economia mundial, como o século da desindustrialização: o caso exemplar da viragem energética alemã deixa evidente que o menor recurso global às fontes convencionais de energia não obsta à inovação e à modernização, antes fomenta e garante o desenvolvimento sustentável da comunidade internacional.

A situação mais avançada da Alemanha no âmbito das energias renováveis não deve, porém, intimidar os restantes países do globo, nem mesmo os estados que com ela fazem parte da União Europeia, sem ostentarem idêntica posição dianteira, antes, pelo contrário, deve animar os respetivos governos a questionarem a sustentabilidade das medidas energéticas adotadas pelos parceiros políticos e económicos alemães, de modo a colherem nos exemplos germânicos práticas eficazes, a curto, médio e longo prazo, de energias renováveis em contexto nacional. O que, desde logo, pressupõe, e exige, a convicta aposta de cada governo nacional não apenas na cabal qualificação dos agentes propulsores das novas soluções energéticas, como também na informação fundada, ampla e sistemática da sociedade civil, pois que ao setor público-estatal se deve, melhor: se tem de 
aliar o domínio privado, de forma a maximizar os benefícios nacionais e, por inerência, internacionais da viragem energética.

\section{Bibliografia}

Berlin Energy Transition Dialogue 2018. Programme. Disponível em: https://www.energiewende2018.com/\#Agenda. [Acedido em 23.12.2018].

BUNDESMINISTERIUM FÜR WIRTSCHAFT UND ENERGIE (ed.). (2016). Erneuerbar. Effizient. Erfolgreich. Deutschlands Weg in eine umweltfreundliche Zukunft, Berlin.

BUNDESMINISTERIUM FÜR WIRTSCHAFT UND ENERGIE (ed.). (2017). Die Energiewende: unsere Erfolgsgeschichte. Berlin.

$\begin{array}{lllllll}\text { BUNDESMINISTERIUM FÜR WIRTSCHAFT UND ENERGIE } & \text { (ed.). } & \text { (2018). } 7 .\end{array}$ Energieforschungsprogramm der Bundesregierung. Berlin.

Gesetz für den Ausbau erneuerbarer Energien (Erneuerbare-Energien-Gesetz - EEG 2017).

Disponível em: http://www.gesetze-im-internet.de/eeg 2014/EEG 2017.pdf .[Acedido em 14.11.2018].

ULRICH, P. \& U. LEHR (2018). Erneuerbar beschäftigt in den Bundesländern. Bericht zur aktualisierten Abschätzung der Bruttobeschäftigung 2016 in den Bundesländern, GWS mbH Osnabrück.

VERBRAUCHERZENTRALE (ed.) (2018), Die neuen Stromzähler kommen. Disponível em: https://www.verbraucherzentrale.de/wissen/umwelt-haushalt/wohnen/die-neuen-stromzaehlerkommen-13275, acedido em 08.12.2018.

ZENTRUM FÜR SONNENENERGIE- UNDWASSERSTOFF-FORSCHUNG BADENWÜRTTEMBERG \& UMWELTBUNDESAMT (ed.). Erneuerbare Energien in Deutschland 2017 Disponível em:

https://www.umweltbundesamt.de/sites/default/files/medien/376/publikationen/180315 uba hg eeinzahlen 2018 bf.pdf [Acedido em 13.10.2018]. 